\title{
CAPÍTOL 11
}

\section{BIBLIOWIKIS: L'ESTUDI DEL GAS CATALÀ DE LES BIBLIOTEQUES COM A PUNT DE REFERÈNCIA PER A NOUS VIQUIPEDISTES I FONTS D'ALTA QUALITAT, DIRIGIT PER VOLUNTARIS}

F. Xavier Dengra i Grau, ${ }^{1}$ Carme Fenoll i Clarabuch, ${ }^{2}$ Vicenç Allué Blanch, ${ }^{3}$ Francesc Fort Silvestre, ${ }^{4}$ Francesc García Grimau, ${ }^{5}$ Amparo Pons Cortell ${ }^{6}$

${ }^{1}$ KU Leuven i Amical Wikimedia, ${ }^{2}$ Universitat Politècnica de

Catalunya, ${ }^{3}$ Universitat Autònoma de Barcelona i Amical Wikimedia, ${ }^{4}$ Amical Wikimedia, ${ }^{5}$ Universitat de Barcelona, ${ }^{6}$ Museu Valencià d'Etnologia i Amical Wikimedia

\section{Resum}

La Viquipèdia en català és una exitosa plataforma de coneixement lliure amb una forta comunitat d'editors que ha contribuiit significativament a normalitzar aquesta llengua minoritzada a Internet. El 2012 l'Associació Amical Wikimedia i el Servei de Biblioteques Públiques del Departament de Cultura de la Generalitat de Catalunya impulsà \#Bibliowikis, una iniciativa que ha implicat diversos centenars de bibliotecaris i biblioteques públiques en la millora d'aquesta versió de l'enciclopèdia en línia. Aquest model únic i reeixit es va presentar a l'Organització de les Nacions Unides per a l'Educació, la Ciència i la Cultura (UNESCO) i ha estat destacat com un cas pràctic per la Federació Internacional d'Associacions i Institucions de Biblioteques (IFLA). El projecte consisteix en 
l'anomenat model Amical, en què la formació en cascada, l'autogestió a llarg termini i la xarxa de voluntaris viquipedistes distribuïts geogràficament constitueixen els tres pilars fonamentals de treball. L'èxit de \#Bibliowikis ha experimentat diferents nivells d'aplicabilitat i regularitat als territoris de parla catalana -especialment al País Valencià i a Andorra- i corre perill per les dinàmiques en línia globals, la pèrdua dels principis de voluntariat i la priorització de recursos econòmics a l'entorn de canvi constant del moviment Wikimedia. Malgrat això, les característiques de \#Bibliowikis estan totalment alineades amb les de l'accés obert, de manera que es combina fàcilment amb el món acadèmic i la transferència de coneixement públic a les universitats. El seu robust discurs ètic sobre contribució social, infraestructura negligible i protecció del patrimoni lingüístic ha permès implementar \#Bibliowikis en el context creixent del teletreball i de la necessitat de digitalització social dels dipòsits bibliogràfics.

\section{Paraules clau}

Català, Wikipedia, Viquipèdia, Biblioteques, Accés obert, Voluntariat, GLAM, Digitalització

Introducció: Llengua catalana, Viquipèdia, geografia i Biblioteques públiques

La llengua catalana és una llengua romànica occidental parlada per aproximadament 10 milions de persones (Plataforma per la llengua, 2020). El seu domini lingüístic natural està format per quatre estats europeus, però no és una llengua dominant en la majoria de les regions on es parla de forma natural: Espanya (comunitats autònomes de Catalunya, País Valencià, Illes Balears, Aragó i Múrcia), França (Department dels Pirineus-Orientals, conegut com a Catalunya del Nord), Andorra, i Itàlia (ciutat sarda de l'Alguer). El català comparteix el seu territori original amb llengües fortes i estatals com el castellà, el francès i l'italià. La fragmentació territorial del català ha donat lloc a diferents denominacions, nivells de protecció i oficialitat segons la regió (Hawkey, 2018; Miller i Miller, 1996). A més, l'ús del català ha estat prohibit diverses vegades al llarg de la història -la darrera censura més significativa a Espanya va tenir 
lloc durant la dictadura franquista (Vallverdú, 1984). El català és una llengua sensible que necessita promocions actives per mantenir viu el seu ús i fomentar la transmissió generacional.

En aquest context lingüístic, la Viquipèdia (Catalan Wikipedia, 2020), l'edició en català de la Wikipedia, va ser la segona edició d'aquest projecte en una llengua diferent de l'anglès (Hinojo, 2016). Va ser la tercera en ésser creada, el març de 2001, tot just després de l'edició en alemany. L'any 2020 apareixia classificada com la vintena llengua per nombre d'articles i tenia una comunitat activa d'uns 1.500 editors mensuals. Des de la seva posada en marxa, tant la Viquipèdia com la resta de projectes Wikimedia s'han demostrat com una eina important per fomentar la normalització del català a Internet i per posar a disposició pública, estructuradament i digital, el coneixement en aquesta llengua (Dengra, 2018; Rius, 2019).

Amical Wikimedia és l'organització sense ànim de lucre que promou la cultura catalana i el coneixement en català de lliure accés a través dels valors i el compromís de les persones i entitats a la Viquipèdia (Amical Wikimedia, 2020b); Amical Wikimedia, 2020c). Ha dut a terme diversos projectes per aconseguir la missió de la Viquipèdia, inclòs el projecte \#Bibliowikis. Des de 2012 Amical Wikimedia s'ha involucrat amb prop de 500 biblioteques públiques, acadèmiques i especialitzades situades als Països Catalans (Proffitt, 2018).

Aquest capítol pretén aprofundir en l'origen, la concepció ètica, el context lingüístic i territorial, les fortaleses i les debilitats del cas d'estudi \#Bibliowikis, que ha estat una iniciativa per apropar els bibliotecaris a l'edició de la Viquipèdia en català i la participació en línia en el coneixement lliure en aquesta llengua. Endemés, aquest capítol proporciona exemples aplicables, algunes estratègies que li permeten vincular-se amb l'acadèmia i alhora discuteix les seves possibilitats futures, amenaces i destí en un món digital i socioeconòmic que canvia ràpidament.

\section{L'inici de \#Bibliowikis a les biblioteques públiques catalanes}

L'any 2011, la relació entre la Viquipèdia en català i l'ecosistema bibliotecari (també aplicable a l'àmbit educatiu) era plena de 
desconfiança. Els bibliotecaris professionals, que havien estat preparats a fi i efecte de buscar a fons en eines de referència tradicionals i altres fonts d'informació contrastades, no veien la Viquipèdia com un aliat, sinó com un intrús del qual no se'n podien refiar. És per aquest motiu que el primer gran pas del 2011, i el veritable detonant cap a una millor relació, va ser la formació dissenyada per Amical Wikimedia juntament amb el Servei de Biblioteques Públiques del Departament de Cultura de la Generalitat de Catalunya (Proffitt, 2018), liderat en aquell moment per Carme Fenoll i Clarabuch.

La primera acció d'aquest projecte va fer possible que la gran majoria de bibliotecaris de la xarxa de biblioteques públiques catalanes aprengués, en detall, els valors de la Viquipèdia, els seus criteris d'edició i el significat dels projectes GLAM (Galeries, Biblioteques, Arxius i Museus) existents. Aquest acord educatiu entre Amical Wikimedia i les biblioteques públiques de Catalunya va tenir lloc principalment entre el 2012 i el 2013. Després, es va dur a terme una formació de seguiment amb bibliotecaris més compromesos i experimentats (Proffitt, 2018). Posteriorment, també es va crear un lema anual que aglutinava les accions de les prop de 400 biblioteques públiques implicades i la campanya anual internacional, \#1Lib1Ref (en català, \#1Bib1Ref), també es va integrar en les activitats \#Bibliowikis amb gran èxit.
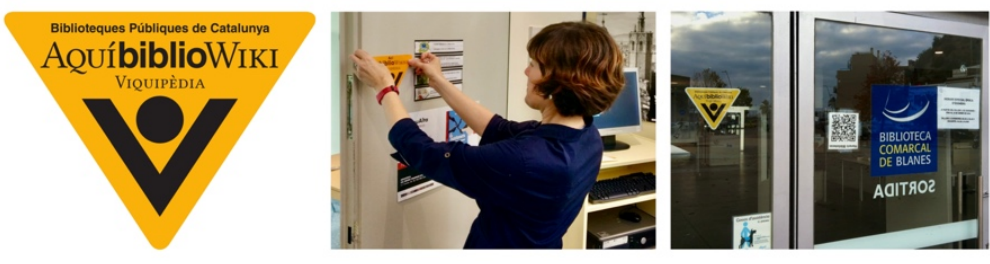

Figura 1 Adhesiu implementat durant els primers anys posteriors al llançament de \#Bibliowikis. Va servir de símbol cohesionant entre les biblioteques participants i va implicar l'interès dels usuaris de les biblioteques públiques en les activitats relacionades amb la Viquipèdia en català. (D'esquerra a dreta: Amical Wikimedia-Servei de Biblioteques de Catalunya, CC-BY-SA 3.0; Francesc Fort, CG-BY-SA 4.0; Àlex Hinojo, CG-BY 3.0). 


\section{Beneficis i oportunitats de la Viquipèdia per als}

bibliotecaris catalans

Què té en comú un viquipedista de divuit anys que treballa des de casa amb un bibliotecari local? La passió per compartir informació i ajudar als ciutadans. Quan aquesta simbiosi va ser reconeguda per viquipedistes i bibliotecaris catalans, la desconfiança inicial va començar a minvar. Els bibliotecaris van aprendre sobre la meritocràcia digital i cohesionada d'una activitat voluntària que complementava l'ètica bibliotecària. D'altra banda, els viquipedistes van conèixer el compromís i la dedicació dels bibliotecaris, l'abast de les colleccions bibliogràfiques pendents de digitalització i els diferents temps d'acció, necessitats i característiques de les institucions públiques. A més a més, la qüestió del biaix de gènere a la Viquipèdia va adquirir més rellevància. En el context català, el $80 \%$ dels bibliotecaris són dones, mentre que el $85 \%$ dels viquipedistes són homes (Roqueta, 2014). La reducció del biaix de gènere a la Viquipèdia es va convertir en un dels majors reptes d'aquest cas d'estudi.

Així mateix, com a llengua minoritzada (Hawkey, 2018; May, 2013), l'edició de la Viquipèdia en català permet als bibliotecaris reforçar el seu paper de promoció de la diversitat lingüística, especialment en el cas de les biblioteques especialitzades en fons locals o patrimonials. Es converteix en una oportunitat per normalitzar i digitalitzar el contingut dels compendis de coneixement en aquesta llengua i alhora visibilitza i exalça a la xarxa els recursos que es poden trobar a les seves biblioteques. Als terrritoris amb un ús baix del català, \#Bibliowikis pot servir als bibliotecaris com a eina per involucrar lingüísticament els seus usuaris i proporcionar-los fonts que no serien consultades en altres circumstàncies.

El model català d'implicació dels bibliotecaris: una filosofia impulsada pel voluntariat

Amical Wikimedia, com a organització sense ànim de lucre d'uns 120 voluntaris, té entre els seus membres diversos dels viquipedistes catalans més actius (Amical Wikimedia, 2020a). Per tant, el doble paper dels voluntaris d'Amical Wikimedia, tant a dins com fora de 
la pròpia Viquipèdia, es converteix en el millor actiu per a la divulgació de l'organització i de l'enciclopèdia lliure. Els voluntaris connecten i es relacionen amb les institucions (és a dir, biblioteques en l'àmbit que ens ocupa) introduint-les als valors de la Viquipèdia. Addicionalment, transfereixen coneixements mitjançant la mentoria d'iniciació, amb suport tècnic i també amb una orientació general per al desenvolupament d'esdeveniments. Finalment, aquests voluntaris (com a viquipedistes experimentats) ja formen part dels mecanismes quotidians i dels debats comunitaris dins dels projectes Wikimedia. Per tant, la integració de nous usuaris, dades i subprojectes en l'àmbit local es considera un creixement natural i anivellat, i no pas com una ingerència externa en una comunitat ja existent (Meta-Wiki, 2014; Wikimedia Outreach, 2017).

D'ençà del 2012 i fins a mitjan 2020, l'estructura i el nucli funcional de l'organització, l'anomenat model Amical, va comptar amb una col-laboració entre un director de projecte i els seus més de 100 voluntaris. Aquest únic empleat era seleccionat d'entre la comunitat viquipedista catalana i tenant en compte la seva participació passada com a voluntari d'Amical. Una petita comissió dels voluntaris més implicats assegurava el seguiment i la direcció professional i rigorosa de les tasques de l'empleat. D'aquesta manera, s'assegurava un vincle horitzontal entre el treballador, la comunitat externa d'editors de la Viquipèdia, els membres interns d'Amical, les institucions col-laboradores externes i els bibliotecaris a títol individual (Meta-Wiki, 2014). No obstant això, la filosofia de l'organització sempre ha estat la de promoure, en darrer terme, l'autosostenibilitat i la formació en cascada dels seus membres i institucions col-laboradores. A l'inici d'un projecte, voluntaris i institucions reben pautes i un voluntari disponible regionalment s'hi serveix de suport humà. Posteriorment, hi ha una disminució progressiva del suport fins que els principiants s'han convertit en voluntaris competents i, finalment, els voluntaris amb la tasca de formadors són alliberats per dedicar-se a d'altres projectes (Fenoll, 2016; Meta-Wiki, 2014; Proffitt, 2018; Wikimedia Outreach, 2017).

Escalant el projecte: El desplegament de \#Bibliowikis a d'altres zones de parla catalana 
Amical Wikimedia ha estat capaç, amb un èxit parcial, d'ampliar l'impacte de \#Bibliowikis fora de Catalunya i d'implementar-lo en altres territoris de parla catalana. El desplegament més significatiu ha estat al País Valencià i Andorra. A més a més, s'ha aconseguit certa activitat esporàdica a la Catalunya Nord i a les Illes Balears. El protagonista d'aquestes primeres expansions va ser Àlex Hinojo Sánchez, director de projectes d'Amical Wikimedia del 2012 al 2018, amb el suport de voluntaris locals i la dinamització d'esdeveniments dirigits i integrats tals com la reunió anual de les biblioteques involucrades, la Trobada de Bibliowikis, que es va celebrar el 2016 (Núvol, 2016).

L'inici de \#Bibliowikis al País Valencià va començar amb una relació entre Amical Wikimedia i el Museu Valencià d'Etnologia el 2016 (Pons, 2019). A finals d'aquell any, el primer viquipedista resident va començar el seu voluntariat a la Biblioteca del Museu Valencià d'Etnologia (Pons, 2019). Aquí, el programa \#Bibliowikis es va adaptar per tal que els seus resultats s'integressin en l'àmbit GLAM. En aquest cas, la biblioteca va actuar com a porta d'entrada al museu. Durant aquesta col-laboració estable, es van carregar documents i fitxers multimèdia als projectes Wikimedia i es van dur a terme diversos concursos d'edició i viquimaratons tals com el concurs Wiki Loves Falles per dotar de més contingut sobre cultura popular el repositori Wikimedia Commons (Pons, 2019). En aquest cas, l'enfocament \#Bibliowikis va afavorir l'adopció del mateix discurs i compromís per part d'un altre ens afiliat del moviment Wikimedia, Wikimedia España, que va refermar la confiança dels bibliotecaris ja involucrats i va augmentar la divulgació lingüística de les activitats en curs.

Tot i que les biblioteques públiques valencianes mai han hostatjat un projecte \#Bibliowikis consolidat com el de Catalunya, aquesta col-laboració híbrida Biblioteques-GLAM amb Amical ha donat el seu fruit amb altres activitats específiques i individuals allotjades en diversos municipis, amb només una edició anual regular a la biblioteca de l'Eliana (Gascó, 2017, 2020) -per bé que aquest esdeveniment concret ha transcendit cap a una activitat plenament autosostenible (Gascó, 2020). Per revertir l'estancament i augmentar el nombre de biblioteques implicades, el Col-legi Oficial 
de Bibliotecaris i Documentalistes de la Comunitat de Valenciana (COBDCV) va signar a finals de 2019 acords formals amb Amical Wikimedia i Wikimedia España que tenen com a objectiu col-laborar, formar i sensibilitzar els professionals valencians cap a projectes i activitats Wikimedia com la campanya \#1Lib1Ref.

De la mateixa manera, la implementació de \#Bibliowikis al microestat d'Andorra ha estat irregular, tot i que majoritàriament exitosa. En aquest cas, dos esdeveniments van ser fonamentals per a la confiança dels bibliotecaris andorrans en el projecte. En primer lloc, el primer article de la Viquipèdia en català i alhora el primer en llengua no angla, Àbac, es va crear a Andorra (Fernández, 2019; Hinojo, 2016). En segon lloc, el Principat d'Andorra es va convertir en el primer estat del món a fotografiar i carregar fitxers de tot el seu patrimoni arquitectònic a la Viquipèdia gràcies a la tenacitat dels voluntaris d'Amical Wikimedia, en el marc de la iniciativa global Wiki Loves Monuments (Govern d'Andorra, 2011; Hinojo, 2016). A mesura que \#Bibliowikis va esdevenir rellevant a Catalunya, la Biblioteca Nacional d'Andorra va prendre el protagonisme el 2013 quan, amb la contribució de la Biblioteca Pública de Govern, ambdues van participar afegint articles a través de la seva primera viquimarató (Hinojo, 2016). Tot i que les biblioteques d'Andorra han reeixit via diversos viquiprojectes, altres iniciatives wiki governamentals, GLAM i universitàries llançades des del país no van incorporar completament el rol bibliotecari els anys posteriors. No obstant això, a l'inici de 2019, la Biblioteca Nacional va tornar a incrementar la seva activitat tot aportant fonts bibliogràfiques $i$ mentoria d'edició a estudiants de secundària i batxillerat (Diari d'Andorra, 2019). A diferència de Catalunya i del País Valencià, però, i atesa la circumstància d'una manca d'editors (o bé desconeguts) al Principat, el suport per fer reeixir a aquest nou tret de sortida va ser proporcionat inicialment i in situ per un voluntari d'Amical des de Catalunya -que progressivament ha anat migrant cap a una mentoria en línia. Malgrat la seva menor activitat respecte d'altres \#Bibliowikis i atenent als impediments derivats de la Llei andorrana de drets d'autor (que no segueix la coneguda com a Llibertat de Panorama), participen amb activitats regulars i autogestionades (per exemple, \#1Lib1Ref) per tal de promoure nous 
continguts i captar nous perfils de voluntaris viquipedistes (Blasco, 2020; Fernández, 2019; Hinojo, 2016).

\section{Fortaleses, debilitats, amenaces $i$ incerteses del model català}

En una dècada, el projecte \#Bibliowikis ha demostrat la seva capacitat per convertir-se en una eina de referència i d'introducció al coneixement obert al públic. La implicació de les biblioteques ha impulsat aquest format $i$ el tàndem viquipedista-bibliotecari s'ha normalitzat. El seu discurs, facilitat d'implementació, cost (gratuiit) i aplicabilitat han permès que el projecte es converteixi en un cas d'estudi internacional. Ha estat avalat per la Fundació Europeana com una oportunitat per aprofundir en els GLAM i en les iniciatives patrimonials (Hinojo, 2013), per la Federació Internacional d'Associacions de Biblioteques i Institucions (IFLA) per a biblioteques públiques (Fenoll, 2016) i fins i tot es va presentar a l'Organització de les Nacions Unides per a l'Educació, la Ciència i la Cultura (UNESCO) (Parreño, 2017). L'impacte i el reconeixement de \#Bibliowikis va ser un impuls crucial per al reconeixement final per part de la Fundació Wikimedia a Amical Wikimedia com el primer ens afiliat i oficial de Wikimedia al món que no està emmarcat en els límits d'un estat sinó en la defensa d'una llengua (Ara, 2013). Un any després, Amical Wikimedia va rebre el Premi Nacional de Cultura 2014 de la Generalitat de Catalunya (Gran Enciclopèdia Catalana, 2015).

La visió adequada d'una plantilla de voluntaris unida a entitats públiques tals com les biblioteques va permetre que \#Bibliowikis creixés significativament. Fins i tot en el cas de menys suport institucional i d'impacte del voluntariat, es van aconseguir bons resultats com ara els codis QR per a elements en dues dimensions que es van carregar a Wikimedia Commons i que van ser presentats per les \#Bibliowikis valencianes en conferències nacionals organitzades per la Federació Espanyola de Societats d'Arxivers, Bibliotecaris, Documentalistes i Museologia (FESABID) (Pons, 2019) -que proven la validesa i la influència social i acadèmica de diferents models de creixement asimètric de les \#Bibliowikis. En tots els casos, les edicions a la Viquipèdia i les càrregues de material multimèdia van contribuir a facilitar la 
comprensió i el desenvolupament de polítiques públiques d'accés obert i, per tant, van esdevenir la llavor principal del canvi.

No obstant això, el model Amical té certes debilitats i incerteses en relació amb les biblioteques. A diferència d'altres iniciatives d'Amical Wikimedia, \#Bibliowikis no té cap cost econòmic, excepte els viatges o despeses bàsiques dels seus voluntaris (Meta-Wiki, 2014). Per tant, el seu afany no depèn de la base monetària, sinó del compromís voluntari i el seu consegüent desenvolupament del discurs public, així com dels bibliotecaris i els seus organismes reguladors per mantenir una formació i un compromís autosostenibles. Una pèrdua vertical en el suport i la projecció institucional, com la que es va produir a Catalunya el 2017 amb el canvi sobtat del cap de Biblioteques Públiques (Martínez, 2017), pot provocar una disminució de l'impacte a mitjà o llarg termini de la iniciativa. De fet, la pèrdua de l'activitat de voluntariat ha fet disminuir les reunions de seguiment, les biblioteques implicades i la ruptura de les activitats consensuades institucionalment amb bibliotecaris de Catalunya pertanyents a les \#Bibliowikis en les darreres etapes.

La robustesa de \#Bibliowikis es basa actualment en l'adopció d'un discurs que recau en els voluntaris actius, en els bibliotecaris i en el reconeixement obtingut. Nogensmenys, hi plana una gran incertesa de futur vinculada a la transmissió d'aquests valors per part de totes les parts implicades. Les prioritats organitzatives i les tasques gestionades pels voluntaris d'Amical han estat limitades a causa de la mida de la comunitat i d'un petit nucli intern de membres molt actius que hi han assumit la major part de la càrrega de treball (MetaWiki, 2014). En futurs entorns de crisi, els bibliotecaris es poden veure afectats per una creixent assignació de tasques professionals $i$, en conseqüència, disminuir la seva disponibilitat per a l'activisme. D'aquesta manera, el destí de \#Bibliowikis podria estar en perill malgrat el seu prestigi. Finalment, l'èxit futur d'aquests i d'altres projectes es veu limitat per dos factors clau. Un d'ells és la manca de renovació generacional de nous viquipedistes amb els mateixos principis i entusiasme de voluntariat que s'havia observat històricament en la comunitat catalana (Hinojo, 2020). Alguns dels seus membres s'han tornat inactius sense realitzar cap transmissió 
prèvia d'experiència als nouvinguts, mentre que alters d'aquests últims no han mostrat prou interès per mantenir-se al dia sobre les iniciatives d'èxit. La segona és la suma de tendències globals equivocades que afecten la Fundació Wikimedia i alguns ens oficials afiliats al món Wikimedia. La quantitat d'empleats i els recursos econòmics s'hi estan convertint en els factors limitants cabdals per a dur a terme activitats, en comptes de l'ecosistema natural de la pròpia Viquipèdia: els voluntaris (Hinojo, 2020). Aquesta deriva ha afectat fortament alguns afiliats de Wikimedia, incloent-hi Amical, on s'hi han desencadenat profunds desacords ètics i de governança que posen en perill la seva continuïtat. En altres territoris, agents externs sense vincles estrets amb les comunitats viquipedistes estan obrint les portes a projectes contractuals amb les biblioteques (Bañares, 2018; Martinsen, 2019). La rendibilitat econòmica podria convertir-se en la tendència i, eventualment, acabar desplaçant les idees benèfiques representades per \#Bibliowikis.

\section{Nexes entre \#Bibliowikis i les biblioteques acadèmiques} Les biblioteques universitàries catalanes s'han convertit en un vincle entre els programes \#Bibliowikis i \#Eduwiki (educatius). Els repositoris institucionals universitaris juguen un paper clau dins de la Viquipèdia: proporcionen accés a les fonts i poden avaluar l'impacte de les llicències Creative Commons en la transferència de coneixement públic des de les institucions d'educació superior al públic general (Universitat Autònoma de Barcelona. Comissió d'Accés Obert, 2020). Les biblioteques acadèmiques tenen una dilatada experiència en la recerca i l'educació en l'accés obert. Per aquest motiu incorporen les seves habilitats i bones pràctiques per promoure els valors del coneixement obert i la seva transferència a les aules, grups de recerca i comunitats administratives, i per tant, en darrera instància, en la divulgació acadèmica. Fruit d'aquest compromís, diverses universitats de l'àmbit catalanoparlant, com ara la Universitat Autònoma de Barcelona (UAB), han actualitzat les seves polítiques institucionals per enriquir la transmissió horitzontal del coneixement amb unes condicions de llicència d'ús compatibles amb la Viquipèdia (Universitat Autònoma de Barcelona, 2012). 
Com s'ha esmentat anteriorment, la figura d'un bibliotecari universitari compromès amb els valors Wikimedia ( $i$, en general, amb el moviment del coneixement lliure) té un gran valor, atès que normalitza el vincle encara reticent amb la comunitat educativa. En el context català, s'han desenvolupat projectes a petita i gran escala que tenen com a objectiu promoure l'impacte acadèmic de la Viquipèdia. Exemples d'aquests sistemes combinats -en els quals les biblioteques universitàries hi han pres protagonisme- són la creació de biografies de persones amb distinció d'Honoris Causa, formacions bibliotecàries en línia durant la pandèmia de la COVID19, alliberament d'imatges d'arxiu a Wikimedia Commons, enllaços ORCID a Wikidata del personal amb admissibilitat acadèmica a la Universitat Autònoma de Barcelona (UAB) (Allué i Casaldàliga, 2018) o l'espai d'edició permanent Viquidones a la Universitat Pompeu Fabra (UPF) (Dengra, 2020; Martija, 2019). Altres activitats han consistit en viquimaratons i viquiprojectes docents avaluables per a alumnes de grau, promoguts conjuntament per bibliotecaris i professors de l'Escola Superior de Música de Catalunya (ESMUC) (Catalunya Ràdio, 2020) o el suport i la mentoria d'instituts per part de la Biblioteca Nacional d'Andorra (Diari d'Andorra, 2019).

En la mateixa línia, els propis bibliotecaris universitaris han contribuït a acords oficials i a llarg termini entre Amical Wikimedia i la UAB, o amb la Universitat Oberta de Catalunya (UOC), amb l'objectiu de promoure tallers, formacions, conferències, compromís amb l'accés obert i especialment projectes \#Eduwiki amb estudiants i professors liderats per voluntaris. Alguns investigadors socials alineats amb el model Amical han integrat el coneixement adquirit en l'àmbit català i en projectes \#Eduwiki i \#Bibliowikis. Han elaborat manuals d'ajuda i guies ètiques sobre l'edició a la Viquipèdia en treballs de final de grau (Castells, 2020), recerca acadèmica altament qualificada i docència regular (Aibar, 2016; Lerga i Aibar, 2015).

Les biblioteques acadèmiques han aconseguit promoure diverses iniciatives que vinculen la docència oberta i la Viquipèdia. Aquests centres disposen de línies de treball relacionades amb el suport al desenvolupament de materials docents oberts i en línia. Per aquesta raó s'han dut a terme alguns esdeveniments relacionats amb l'educació de lliure accés, com ara l'Open Education Week (Solé, 
2020). Sota el títol «Recursos educatius en oberts: comparteix per educar», la UAB va acollir una jornada de treball dedicada a abordar iniciatives educatives obertes en el marc dels programes Wikimedia i amb la participació de bibliotecaris, professors i viquipedistes (Universitat Autònoma de Barcelona Servei de Biblioteques, 2020). Els bibliotecaris universitaris són un exemple de transició cap a una priorització de l'entorn digital. En aquest context i enmig de l'experiència de la COVID-19, les iniciatives de servei públic amb valor afegit i presencialitat reduits, representades per exemples com \#Bibliowikis, poden jugar un paper important en la recerca d'objectius comuns amb poca interacció física. A tots els nivells educatius ja s'està proposant una reformulació dels enfocaments didàctics, amb l'addició de nous entorns d'aprenentatge a distància que siguin agradables i la inserció de les tecnologies d'ús que definiran les noves generacions (Rapanta et al., 2020).

\section{Conclusions}

La dificultat principal a la qual s'enfronten els bibliotecaris que editen la Viquipèdia ha estat la manca de temps i la impossibilitat d'integrar naturalment l'edició en la seva rutina diària: els bibliotecaris necessàriament prioritzen l'ordenació bibliogràfica i el servei de referència presencial als taulells. La filosofia reeixida de \#Bibliowikis ha confiat en els valors del voluntariat, la conversió de nous editors i la seva formació en cascada, que han evolucionant asimètricament entre bibliotecaris i viquipedistes en un entorn Wikimedia i sociodigital molt canviants. No obstant això, \#Bibliowikis ha fet palès el seu èxit jugant un paper important a l'hora d'oferir una resposta a l'interès d'una comunitat que vol treballar orgullosament en projectes semblants de divulgació independentment de la seva edat, coneixement acadèmic, gènere, ubicació i àdhuc distanciament social. Endemés, ha creat vincles entre bibliotecaris a través de diferents tipologies de biblioteques. \#Bibliowikis, atesa la seva estructura lliure i d'ús franc, fiable i organitzada pel voluntariat, pot ser també un model per a sistemes de biblioteques fora dels Països Catalans. Els bibliotecaris haurien de prioritzar la inclusió de l'educació oberta i d'objectius per al 
coneixement lliure, que són fomentats per casos d'estudi com el de \#Bibliowikis.

\section{Referències}

Aibar Puentes, Eduard. (2016). «Guia de recomanacions i bones pràctiques per a editar el contingut científic de Viquipèdia». http://hdl.handle.net/10609/57384.

Allué, Vicenç; Casaldàliga, Núria. (2018). «Viquipèdia i UAB, una relació amb perspectives de futur». Biblioteca Informacions.

https://blogs.uab.cat/bibliotecainformacions/2018/12/1 9/viquipedia-i-uab-una-relacio-amb-perspectives-defutur-allue-vicenc-casaldaliga-nuria/.

Amical Wikimedia. (2020a). «Amical Wikimedia». A Wikimedia. https://meta.wikimedia.org/wiki/Amical_Wikimedia (en anglès).

Amical Wikimedia. (2020b). «Bylaws». (2020). A Wikimedia. https://meta.wikimedia.org/wiki/Amical_Wikimedia/B ylaws (en anglès).

Amical Wikimedia. (2020c). «Qui som». https://www.wikimedia.cat/presentacio/.

Bañares, Ilya. (2018). «U of T Libraries hires first Wikipedian in residence». Toronto Star. www.thestar.com/news/gta/2018/11/01/u-of-tlibraries-hires-first-wikipedian-in-residence.html (en anglès).

Blasco, Joan Josep. (2020). «Les biblioteques enriqueixen la xarxa». El Periòdic d'Andorra. www.elperiodic.ad/noticia/77532/les-bibliotequesenriqueixen-la-xarxa. 
Castells, Eva. (2020). «Treball de Fi de Grau d'edició de la Viquipèdia. Manual d'ajuda». https://ddd.uab.cat/record/218016.

Catalan Wikipedia. (2020). A Wikipedia. https://en.wikipedia.org/wiki/Catalan_Wikipedia (en anglès).

Catalunya Ràdio. (2020). «Amb la Viquimarató, el treball que es fa a l'Escola no queda a l'aula, sinó que arriba a la societat». Corporació Catalana de Mitjans Audiovisuals. www.ccma.cat/catradio/alacarta/assaig-general/amb-laviquimarato-el-treball-que-es-fa-a-lescola-no-queda-alaula-sino-que-arriba-a-la-societat/audio/959201/.

Dengra i Grau, F. Xavier. (2018). «És cert allò fiable? Els mecanismes de rigor de la Viquipèdia». Terminàlia, 18, 50-52. www.doi.org/10.2436/20.2503.01.126.

Dengra i Grau, F. Xavier. (2020). «Viquiprojecte:UAB. Espai de formació docent». https://ca.wikipedia.org/wiki/Viquiprojecte:UAB/Form aci\%C3\%B3_docent.

Diari Ara. (2013). «L'associació Amical Wikimedia rep el reconeixement internacional després de cinc anys de lluita per aconseguir-ho». Diari Ara. www.ara.cat/tecnologia/Lassociacio-AmicalWikimedia-reconeixementinternacional_0_933506826.html.

Diari d'Andorra. (2019). «Sandy ja té qui n'escrigui». Diari d'Andorra. www.diariandorra.ad/noticies/cultura/2019/05/14/sand y_qui_escrigui_145786_1127.html.

Fenoll, Carme. (2016). «Opportunities for public libraries and Wikipedia». International Federation of Library 
Associations and Institutions.

www.ifla.org/files/assets/hq/topics/info-

society/iflawikipediaandpubliclibraries.pdf (en anglès).

Fernández, Júlia. (2019). «Tot un "viqui-univers" al teu servei».

Diari Bondia Andorra. www.bondia.ad/opinio/tot-unviqui-univers-al-teu-servei.

Gascó Comeche, Barbara. (2020). «Viquiprojecte l'Eliana:

Història Local a Viquipèdia». Bastida, 2, 25.i

Gascó Comeche, Barbara. (2017). «Viquiprojecte l'Eliana:

Història local a la Viquipèdia». Símile, 37.

Generalitat Valenciana (2018). «Mapa de Biblioteques de la Comunitat Valenciana».

http://webapp.cult.gva.es/hdfi/ESLAB-

BIBLIO/bibliotecas_cpru.jsp (en castellà).

Govern d'Andorra. (2011). «La imatge de Sant Joan de

Caselles, guanyadora de l'edició Wiki Loves

Monuments 2011 d'Andorra».

www.govern.ad/cultura/item/3370-la-imatge-de-santjoan-de-caselles-guanyadora-de-l'edició-wiki-lovesmonuments-2011-andorra.

Gran Enciclopèdia Catalana. (2015). «Wikipedia». www.enciclopedia.cat/ec-gec-0283878.xml.

Hawkey, James. (2018). Language attitudes and minority rights: The case of Catalan in France. Palgrave Macmillan. https://doi.org/10.1007/978-3-319-74597-8 (en anglès).

Hinojo, Àlex. (2013). «How Europeana helps Wikipedia editor and GLAM ambassador». Europeana Foundation. https://pro.europeana.eu/post/how-europeana-helpswikipedia-editor-and-glam-ambassador (en anglès). 
Hinojo, Àlex. (2016). «Viquipèdia i Andorra». Ex-libris Casa Bauró, 19.

www.cultura.ad/images/stories/Accio_Cultural/Publica cions/ex-libris/2016/Ex-Libris_19-2016.pdf.

Hinojo, Àlex. (2020). «Somien els viquipedistes en enciclopèdies elèctriques? Present i futur de la Viquipèdia i el rol de la comunitat catalanoparlant». Revista de Llengua i Dret, Journal of Language and Law, 73, 133-45. https://doi.org/10.2436/ rld.i73.2020.3424.

Lerga Felip, Maura; Aibar Puentes, Eduard. (2015). Best practice guide to use Wikipedia in university education. http://hdl.handle.net/10609/41662 (en anglès).

Martija, Patricia. (2019). «Las editoras que feminizan Wikipedia». Metrópoli Abierta.

www.metropoliabierta.com/quien-hacebarcelona/entidades/editoras-feminizanwikipedia_14269_102.html (en castellà).

Martínez, Dídac. (2017). «El cas Carme Fenoll». Núvol. www.nuvol.com/llibres/el-cas-carme-fenoll-43208.

Martinsen, Jorid. (2019). «Oslo Metropolitan University hires "Wikipedia-assistants" ». Wikimedia Outreach. https://outreach.wikimedia.org/wiki/Education/News/ February_2019/Oslo_Metropolitan_University_hires_ \%E2\%80\%9CWikipedia-assistants\%E2\%80\%9D (en anglès).

May, Stephen. (2013). Language and minority rights: Ethnicity, nationalism and the politics of language. Routledge. ISBN 9781136837067 (en anglès).

Meta-Wiki. (2014). «Organizational effectiveness/case studies/Amical Wikimedia». 
https://meta.wikimedia.org/wiki/Organizational_effecti veness/Case_studies/Amical_Wikimedia (en anglès).

Miller, H., \& Miller, K. (1996). «Language policy and identity: The case of Catalonia». International Studies in Sociology of Education, 6(1), 113-28 (en anglès).

Núvol. (2016). «Bibliowikis, un model a seguir». Núvol. https://www.nuvol.com/llibres/bibliowikis-un-modela-seguir-41450.

Parreño Mont, David. (2017). «Amical Wikimedia presenta a la UNESCO la col-laboració amb les biblioteques». Amical Wikimedia. www.wikimedia.cat/2017/02/21/amical-wikimediapresenta-la-collaboracio-amb-les-biblioteques-a-launesco/.

Plataforma per la llengua. (2020). «InformeCat 2020: 50 dades sobre la llengua». www.plataformallengua.cat/media/upload/pdf/informecat2020_267_11_2406.pdf.

Pons Cortell, A.; Fort Silvestre, F. J., et al. (2019). «Un wikipedista en la Biblioteca del Museu Valencià d'Etnologia». Cuartas Jornadas sobre bibliotecas de museos: Estrategias sostenibles y alianzas en bibliotecas de museos. Actas de las IV Jornadas BIMUS, 121-36. https://dialnet.unirioja.es/servlet/articulo? codigo $=7246$ 951 (en castellà).

Proffitt, Merrilee. Leveraging Wikipedia: Connecting communities of knowledge. American Library Association. ISBN 9780838916322 (en anglès).

Rapanta, C., Botturi, L., Goodyear, P., et al. (2020). «Online university teaching during and after the Covid-19 crisis: Refocusing teacher presence and learning 
activity». Postdigit Sci Educ, 2, 923-45.

https://doi.org/10.1007/s42438-020-00155-y (en anglès).

Rius, Clàudia. (2019). «Internet, els influencers i la normalització del català». Núvol. www.nuvol.com/llengua/internet-els-influencers-i-lanormalitzacio-del-catala-62248.

Roqueta, Marta. (2014). «Com és que no hi som?» Revista Digital Dones. www.donesdigital.cat/noticia/981/comes-que-no-hi-som/.

Solé, Esther. (2020). «La Viquipèdia segueix consolidant-se com l'eina acadèmica lliure a l'Open Education Week de la UAB». Biblioteca Informacions. https://blogs.uab.cat/bibliotecainformacions/2020/04/1 5/la-viquipedia-segueix-consolidant-se-com-leinaacademica-lliure-a-lopen-education-week-de-la-uabsole-i-marti-esther/.

Universitat Autònoma de Barcelona. Comissió d'Accés Obert. (2020). «Creative Commons licenses recommended in the UAB.» https://ddd.uab.cat/record/129205 (en anglès).

Universitat Autònoma de Barcelona. Consell de Govern (2012). «Open access institutional policy». https://ddd.uab.cat/record/89641 (en anglès).

Universitat Autònoma de Barcelona. Servei de Biblioteques (2020). «Recursos educatius en obert: comparteix per educar: Jornada sobre iniciatives docents en el marc de la viquipèdia.» https://ddd.uab.cat/search?f=publication $\& \mathrm{p}=$ Open $\% 20$ Education\%20Week\&ln=ca. 
Vallverdú, F. (1984). «A sociolinguistic history of Catalan». International Journal of the Sociology of Language, 47. https://doi.org/10.1515/ijsl.1984.47.13 (en anglès).

Wikimedia Outreach. (2017). «GLAM/case studies/Catalonia’s network of public libraries». https://outreach.wikimedia.org/wiki/GLAM/Case_stud ies/Catalonia\%27s_Network_of_Public_Libraries (en anglès). 